trượt đốt sống đoạn thắt lưng cùng một tâng bằng phẫu thuât vít cuổng cung qua da và ghép xương liên thân đốt, Luận án tiến sĩ Y học, Học viện Quân y. 8. Choi W.-S., Kim J.-S., Ryu K.-S. và cộng sự.
(2016). Minimally Invasive Transforaminal Lumbar Interbody Fusion at L5-S1 through a Unilateral Approach: Technical Feasibility and Outcomes. BioMed Res Int, 2016, 2518394.

\title{
ĐÁNH GIÁ KẾT QUẢ NGẮN HẠN NONG BÓNG VÀ ĐĂT GIÁ Đỡ TRONG ĐIỀU TRI TẮC ĐộNG MẠCH CHẬU TASC II A, B
}

\author{
Lê Đức Tín*, Phạm Minh Ánh*, Đỗ Kim Quế**
}

\section{TÓM TẮT}

Mục tiêu: Đánh giá kết quả ngắn hạn nong bóng và đặt giá đỡ trong điêu trị tắc động mạch chậu TASC II $A$, B. Phương pháp: hồi cứu mô tả. Kết quả: Nghiên cứu có 137 bệnh nhân, nam chiếm 84,7\%, tuổi trung bình 70,4 $\pm 10,9$ mẫu nghiên cứu. Phân đố TASC II A chiếm 48,9\% (67 trường hợ), phân đổ TASC II B chiếm $51,1 \%$ (70 trường hợp). Nhóm nong bóng đơn thuần có tỷ lệ phân loai $B$ thấp hơn nhóm đặt giá đỡ $(28,6 \%$ so với $63,6 \%, p<0,001)$. Thời gian can thiêp trung bình của nhóm nong bóng và đăt giá đỡ lần lượt chiểm $157 \pm 39,7$ phút và $147 \pm 56,4$ phút. Thời gian nằm viên trung binh của nhóm nong bóng và đặt giá đỡ lần lượt chiểm là $4,4 \pm 1,7$ ngày và $4,8 \pm 3,1$ ngày. Biến chứng chung chiếm $4,4 \%$, trong đó tắc mạch $0,73 \%$, nhồi máu cơ tim $0,73 \%$, cắt cưt $1,5 \%$, tụ máu đường vào $0,73 \%$, suy thấn $0,73 \%$ mâ̂u nghiên cứu. Kết quả thành công về kỹ thuật nong bóng và đặt giá đỡ lần lượt chiểm 95,9\% và $96,6 \%$ mẫu nghiên cứu. Thành công về mặt lâm sàng ở giai đoan ngắn hạn của nong bóng và đặt giá đỡ lần lượt chiếm $97,9 \%$ và $96,7 \%$, khác biệt không có ý nghĩa thống kê $(P=0,67)$. Kết luận: Nong bóng và đặt giá đỡ trong điều trị tắc động mach chậu tổn thương TASC II A, B là ít xâm lấn, an toàn, hiệu quả, thời gian nằm viên ngắn, hồi phục nhanh. Cả hai phương pháp đều cải thiện các triệu chứng lâm sàng và cận lâm sàng sau can thiêp, ít biến chứng. Tỷ lê thành công về lâm sàng ở giai đoạn ngắn hạn của phương pháp nong bóng và đăt giá đỡ tương đương nhau.

Từ khóa: tắc động mạch chậu, nong bóng, đặt giá đỡ, TASC II A, B.

\section{SUMMARY \\ COMPARED SHORT-TERM RESULTS OF \\ BALLOON ANGIOPLASTY AND STENT PLACEMENT THERAPY FOR TASC II A, B LESIONS OF ILIAC ARTERIAL OCCLUSIONS \\ Objective: To compare the results of balloon angioplasty and stent placement therapy for TASC II A, B lesions of iliac arterial occlusions. Methods: Retrospective descriptive series of cases. Results:}

*Bênh viện Chợ Rẫy

**Bệnh viện Thống Nhất

Chịu trách nhiệm chính: Lê Đức Tín

Email: ductin@ump.edu.vn

Ngày nhận bài: 15.7.2021

Ngày phản biên khoa hoc: 10.9.2021

Ngày duyệt bài: 17.9.2021
The study had 137 patients, male accounted for $84.7 \%$, average age $70.4 \pm 10.9$ study samples. TASC II A class accounted for $48.9 \%$ (67 cases), TASC II B class accounted for $51.1 \%$ (70 cases). The balloon angioplasty group had a lower percentage of TASC II $B$ than the stent placement group $(28.6 \%$ vs $63.6 \%$, $p<0.001)$. The mean intervention time of the balloon angioplasty and stent placement group accounted for $157 \pm 39.7$ minutes and $147 \pm 56.4$ minutes, respectively. The mean hospital stay of the balloon angioplasty and stent placement group was $4.4 \pm 1.7$ days and $4.8 \pm 3.1$ days, respectively. General complications accounted for $4.4 \%$ of the sample, of which embolism $0.73 \%$, myocardial infarction $0.73 \%$, amputation $1.5 \%$, hematoma $0.73 \%$, renal failure 0.73 of the sample. Technically successful results are $100 \%$ for both methods. The short-term clinical success of balloon angioplasty and stenting accounted for $97.9 \%$ and $96.7 \%$, respectively, the difference was not statistically significant $(p=0.67)$. Conclusions: Angioplasty and stenting in the treatment of iliac artery occlusion with TASC II A, B lesions are minimally invasive, safe, effective, short hospital stay, and fast recovery. Both methods improve clinical and subclinical symptoms after the intervention, with few complications. The short-term clinical success between PTA and stent placement was not statistically significant.

Key words: Angioplasty, stent placement, iliac arterial occlusions, TASC II A, B.

\section{I. ĐĂT VẤN ĐỀ}

Tắc động mạch mạn tính chi dưới là bệnh lý thường gặp, bệnh thường diễn tiến âm thầm nên khi bệnh nhân đến khám và điều trị thường ở giai đoạn muộn. Theo thống kê, Châu Âu và Bắc Mỹ có khoảng 27 triệu người bị mắc bệnh này. Tại Mỹ, theo nghiên cứu của John W. York và Spence M. Taylor [1], mỗi năm có hơn 10 triệu người mắc bệnh tắc động mạch chi dưới, trong đó bệnh nhân trên 70 tuổi chiếm $14,5 \%$, có trên 100.000 bệnh nhân cần phải điều trị tái lưu thông mạch máu, trong đó cắt cụt chi chiếm từ 1 đến 7\% tất cả các trường hợp. Tại Việt Nam, theo nghiên cứu của Viện Tim Mạch Việt Nam, tỷ lệ bệnh động mạch chi dưới tắng đáng kế từ $1,7 \%$ (năm 2003) lên đến 3,4\% (năm 2007) [1].

Theo phân loại tổn thương TASC II đối với tầng chủ - chậu, can thiệp nội mạch là phương pháp ưu tiên chọn lựa điều trị tổn thương TASC 
II A, B. Tuy nhiên, trong quá trình thực hành chúng tôi nhận thấy chưa có nhiều công trình nghiên cứu so sánh kết quả nong bóng và đặt giá đỡ trong điều trị tổn thương tânng động mạch chậu TASC II A, B. Đó là lý do để chúng tôi tiến hành nghiên cứu về loại phương pháp can thiệp nội mạch trong tắc động mạch chậu TASC II A, B. Và câu hỏi mà chúng tôi đặt ra là: kết quả của nong bóng so đặt giá đõ trong điều trị tắc động mạch chậu tổn thương TASC II A, B như thế nào?

\section{II. ĐỐl TƯợNG VÀ PHƯƠNG PHÁP NGHIÊN CƯU \\ 2.1 Phương pháp nghiên cứu}

Thiết kế nghiên cứu: hồi cứu mô tả.

Thời gian nghiên cứu: từ tháng 10 năm 2016 đến tháng 06 năm 2020.

Địa điểm nghiên cứu: bệnh viện Chợ Rẫy.

\section{2 Đối tượng nghiên cứu}

\section{Tiêu chuân chọn mẫu:}

- Tất cả những trường hợp có bệnh tắc động mạch chậu tổn thương TASC II $A, B$ điều trị bằng phương pháp can thiệp tã̃i khoa Phẫu thuật Mạch máu, bệnh viện Chợ Rẫy.

- Nếu có tổn thương tâng dưới tâng chậu: phải được can thiệp tái thông đảm bảo:

+ Lâm sàng cải thiện với Rutherford > 1 độ sau can thiệp.

+ ABI đạt > 0.75 sau can thiệp

+ Siêu âm: đường kính lòng mạch sau can thiệp không hẹp tôn lưu > 50\% hoặc tắc.

Tiêu chuẩn loại trừ:

- Bệnh nhân tắc động mạch chậu mạn tính được điều trị bằng phẩu thuật Hydrid: phẫu thuật kết hợp can thiệp nội mạch.

- Bệnh tắc động mạch chậu mạn tính do viêm, bệnh tự miểm như Takayasu. cụt chi

Bệnh tắc động mạch chậu mạn tính phải cắt

- Bệnh tắc động mạch chậu mạn tính không triệu chứng.

Đánh giá kết quả can thiệp:

Đánh giá kết quả chu phấu: nhỏ hơn 01 tháng sau can thiệp.

- Đánh giá kết quả can thiệp: tuổi, giới, các yếu tố nguy cơ và bệnh phối hợp, phân độ Rutherford, ABI, TASC II, phương pháp vô cảm, đường vào, loại bóng và giá đõ.

- Đánh giá tỷ lệ thành công, thất bại về kỹ thuật: Thành công vê kỹ thuật khi: đường kính lòng mạch sau can thiệp hẹp tôn lưu < 30\%, không có bóc tách, vơ mạch và tụ máu sau nong bóng, không xoắn vặn hoặc gập gãy giá đỡ, không gây huyết khối tắc đâu xa khi chụp DSA ngay sau can thiệp, không có biến chứng cắt cụt chi.

- Đánh giá các biến chứng can thiệp: tắc mạch, thủng ĐM can thiệp, tụ máu đường vào, suy thận cấp, cắt cụt chi, giả phình đường vào, nhôi máu cơ tim và tử vong.

Đánh giá kết quả ngắn hạn: từ 01 tháng đến 12 tháng sau can thiệp.

- Đánh giá kết quả lâm sàng, cận lâm sàng.

- Đánh giá tỷ lệ thành công, thất bại về lâm sàng:

- Thành công về lâm sàng khi: khi kết quả lâm sàng đạt mức cải thiện rỗ rệt, cải thiện vừa phải, cải thiện ít theo tiêu chuẩn của SVS/ISĊVS(3).

\section{KẾT QUẢ NGHIÊN CỨU}

Mẫu có 137 trường hợp thỏa tiêu chuẩn chọn bệnh.

Giới, tuổi

\begin{tabular}{|c|c|c|c|c|}
\hline & $\begin{array}{c}\text { Tống } \\
(\mathrm{N}=137)(\%)\end{array}$ & $\begin{array}{l}\text { Nong bóng } \\
(N=49)(\%)\end{array}$ & $\begin{array}{c}\text { Đắt giá đõ̃ } \\
(\mathbf{N}=\mathbf{8 8})(\%)\end{array}$ & Giá trị p \\
\hline Giới tính: Nữ & $21(15,3)$ & $13(26,5)$ & $8(9,1)$ & \multirow{2}{*}{$0,014^{a}$} \\
\hline Nam & $116(84,7)$ & $36(73,5)$ & $80(90,9)$ & \\
\hline Tuổi (năm) & $\begin{array}{l}70,4 \pm 10,9 \\
47,0-97,0\end{array}$ & $\begin{array}{c}73,8 \pm 10,9 \\
52,0-97,0\end{array}$ & $\begin{array}{c}68,5 \pm 10,4 \\
47,0-94,0\end{array}$ & $0,007^{b}$ \\
\hline Nhóm tuổi: <60 & $23(16,8)$ & $5(10,2)$ & $18(20,5)$ & \multirow{4}{*}{$0,045^{a}$} \\
\hline $60-69$ & $45(32,8)$ & $12(24,5)$ & $33(37,5)$ & \\
\hline $70-79$ & $41(29,9)$ & $17(34,7)$ & $24(27,3)$ & \\
\hline$\geq 80$ & $28(20,4)$ & $15(30,6)$ & $13(14,8)$ & \\
\hline
\end{tabular}

Các yếu tố nguy cơ, bệnh phối hợp:

Bảng 1: Tuối, giới và các yếu tốnguy cơ, bệnh phôi hợp

\begin{tabular}{|c|c|c|c|c|}
\hline & $\begin{array}{c}\text { Tống } \\
(\mathrm{N}=137)(\%)\end{array}$ & $\begin{array}{l}\text { Nong bóng } \\
(\mathrm{N}=49)(\%)\end{array}$ & $\begin{array}{c}\text { Đắt giá đõ } \\
(\mathrm{N}=88)(\%)\end{array}$ & Giá trị p \\
\hline Hút thuốc lá & $92(67,2)$ & $27(55,1)$ & $65(73,9)$ & $0,040^{a}$ \\
\hline Số gói-năm & $\begin{array}{l}30,5 \pm 7,7 \\
10,0-50,0\end{array}$ & $\begin{array}{l}28,4 \pm 7,2 \\
20,0-50,0\end{array}$ & $\begin{array}{l}31,5 \pm 7,8 \\
10,0-40,0\end{array}$ & $0,072^{b}$ \\
\hline RLCHM & $56(40,9)$ & $19(38,8)$ & $37(42,0)$ & $0,85^{\mathrm{a}}$ \\
\hline
\end{tabular}


VIETNAM MEDICAL JOURNAL N01 - OCTOBER - 2021

\begin{tabular}{|c|c|c|c|c|}
\hline THA & $78(56,9)$ & $32(65,3)$ & $46(52,3)$ & $0,19^{\mathrm{a}}$ \\
\hline ĐTĐ & $49(35,8)$ & $23(46,9)$ & $26(29,5)$ & $0,064^{\mathrm{a}}$ \\
\hline Bềnh ĐM cảnh & $53(38,7)$ & $21(42,9)$ & $32(36,4)$ & $0,57^{\mathrm{a}}$ \\
\hline Bệnh ĐM vành & $6(4,4)$ & $2(4,1)$ & $4(4,5)$ & $>0,99^{\mathrm{c}}$ \\
\hline COPD & $16(11,7)$ & $9(18,4)$ & $7(8,0)$ & $0,12^{\mathrm{a}}$ \\
\hline Suy tim & $3(2,2)$ & $2(4,1)$ & $1(1,1)$ & $0,29^{\mathrm{c}}$ \\
\hline Suy thận mạn & $2(1,5)$ & $0(0)$ & $2(2,3)$ & $0,54^{\mathrm{c}}$ \\
\hline
\end{tabular}

Phân đồ Rutherford và ABI:

Bảng 2: Phân độ theo Rutherford.

\begin{tabular}{|c|c|c|c|c|}
\hline & $\begin{array}{c}\text { Tống } \\
(\mathrm{N}=137)(\%)\end{array}$ & $\begin{array}{l}\text { Nong bóng } \\
(\mathrm{N}=49)(\%)\end{array}$ & $\begin{array}{c}\text { Đắt giá đỡ } \\
(N=88)(\%)\end{array}$ & Giá trị p \\
\hline Phân độ Rutherford & & & & $0,13^{a}$ \\
\hline Không triệu chứng & $0(0)$ & $0(0)$ & $0(0)$ & \\
\hline Độ I & $0(0)$ & $0(0)$ & $0(0)$ & \\
\hline Độ II & $6(4,4)$ & $3(6,1)$ & $3(3,4)$ & \\
\hline Độ III & $55(40,1)$ & $13(26,5)$ & $42(47,7)$ & \\
\hline Độ IV & $12(8,8)$ & $5(10,2)$ & $7(8,0)$ & \\
\hline Độ V & $51(37,2)$ & $24(49,0)$ & $27(30,7)$ & \\
\hline Độं VI & $13(9,5)$ & $4(8,2)$ & $9(10,2)$ & \\
\hline ABI & $0,3 \pm 0,2(0,0-0,9)$ & $0,3 \pm 0,2(0,0-0,9)$ & $0,3 \pm 0,2(0,0-0,7)$ & $0,57^{b}$ \\
\hline
\end{tabular}

Phân loại TASC II:

Bảng 3: Phân loai theo TASC II.

\begin{tabular}{|c|c|c|c|c|}
\hline & $\begin{array}{c}\text { Tống } \\
(\mathbf{N}=\mathbf{1 3 7})(\%)\end{array}$ & $\begin{array}{c}\text { Nong bóng } \\
(\mathbf{N}=\mathbf{4 9})(\mathbf{\%})\end{array}$ & $\begin{array}{c}\text { Đă̆t giá đỡ } \\
(\mathbf{N}=\mathbf{8 8})(\mathbf{\%})\end{array}$ & Giá trị p \\
\hline Phân độ TASC II & & & & $<\mathbf{0 , 0 0 1}^{\mathbf{a}}$ \\
\hline A & $67(48,9)$ & $35(71,4)$ & $32(36,4)$ & \\
\hline B & $70(51,1)$ & $14(28,6)$ & $56(63,6)$ & \\
\hline
\end{tabular}

Kết quả chu phầu:

Phương pháp vô cảm

Bảng 4: Phương pháp vô cảm

\begin{tabular}{|c|c|c|c|c|}
\hline & $\begin{array}{c}\text { Tống } \\
(\mathrm{N}=137)(\%)\end{array}$ & $\begin{array}{l}\text { Nong bóng } \\
(\mathrm{N}=49)(\%)\end{array}$ & $\begin{array}{c}\text { Đăht giá đỡ } \\
(\mathbf{N}=\mathbf{8 8})(\%)\end{array}$ & Giá trị p \\
\hline Vô cảm & & & & $>0,99^{a}$ \\
\hline Mê NKQ & $14(10,2)$ & $5(10,2)$ & $9(10,2)$ & \\
\hline Têt tủy sống & $0(0)$ & $0(0 \%)$ & $0(0)$ & \\
\hline Tê tại chô & $123(89,8)$ & $44(89,8)$ & $79(89,8)$ & \\
\hline $\begin{array}{l}\text { Thời gian can thiệp } \\
\text { (phút) }\end{array}$ & $\begin{array}{l}150,8 \pm 51,3 \\
40,0-310,0\end{array}$ & $\begin{array}{l}157,0 \pm 39,7 \\
60,0-240,0\end{array}$ & $\begin{array}{c}147,3 \pm 56,7 \\
40,0-310,0 \\
\end{array}$ & $0,24^{b}$ \\
\hline $\begin{array}{l}\text { Thời gian nằm viện } \\
\text { (ngày) }\end{array}$ & $\begin{array}{l}4,7 \pm 2,7 \\
2,0-25,0\end{array}$ & $\begin{array}{r}4,4 \pm 1,7 \\
2,0-8,0\end{array}$ & $\begin{array}{l}4,8 \pm 3,1 \\
2,0-25,0\end{array}$ & $0,38^{\mathrm{b}}$ \\
\hline
\end{tabular}

Đăc điếm chi can thiệp:

Bảng 5. Đặc điểm chỉ can thiệp

\begin{tabular}{|c|c|c|c|c|}
\hline & $\begin{array}{c}\text { Tống } \\
(\mathrm{N}=137)(\%)\end{array}$ & $\begin{array}{l}\text { Nong bóng } \\
(\mathrm{N}=49)(\%)\end{array}$ & $\begin{array}{c}\text { Đăht giá đõ } \\
(\mathbf{N}=88)(\%)\end{array}$ & Giá trị p \\
\hline Vị trí đường vào & & & & $0,007^{b}$ \\
\hline ĐM் đùi cùng bên & $57(41,6)$ & $14(28,6)$ & $43(48,9)$ & \\
\hline ĐM đùi đối bên & $64(46,7)$ & $32(65,3)$ & $32(36,4)$ & \\
\hline ĐM cánh tay & $13(9,5)$ & $2(4,1)$ & $11(12,5)$ & \\
\hline ĐM khoeo & $3(2,2)$ & $1(2,0)$ & $2(2,3)$ & \\
\hline Tầng can thiệp & & & & $0,13^{\mathrm{a}}$ \\
\hline Chậu chung & $54(39,4)$ & $14(28,6)$ & $40(45,5)$ & \\
\hline Chậu ngoài & $55(40,1)$ & $22(44,9)$ & $33(37,5)$ & \\
\hline Cả 2 & $28(20,4)$ & $13(26,5)$ & $15(17,0)$ & \\
\hline \multicolumn{2}{|c|}{ Tầng can thiệp (dưới chậu kèm theo) } & & & $<0,001^{b}$ \\
\hline Đùi khoeo & $78(56,9)$ & $31(63,3)$ & $47(53,4)$ & \\
\hline Dưới gối & $2(1,5)$ & $1(2,0)$ & $1(1,1)$ & \\
\hline
\end{tabular}




\begin{tabular}{|c|c|c|c|c|}
\hline Cả 2 & $8(5,8)$ & $8(16,3)$ & $0(0)$ & \\
\hline Kích thước bóng $(\mathrm{mm})$ & & $6,5 \pm 0,7(5,0-8,0)$ & - & - \\
\hline Loại bóng & & & - & \\
\hline Ap lực & & $0(0,0 \%)$ & - & \\
\hline Không áp lực & & - & $7,3(100,0 \%)$ & \\
\hline Kích thước giá đỡ $(\mathrm{mm})$ & & - & $82(93,3 \%)$ & - \\
\hline Loại giá đỡ & & - & $6(6,7 \%)$ & \\
\hline Tự bung & & - & & \\
\hline Bung băng bóng & & &
\end{tabular}

Biến chứng sau can thiệp

Bảng 6: Biến chứng sau can thiệp

\begin{tabular}{|c|c|c|c|c|}
\hline & $\begin{array}{c}\text { Tống } \\
(\mathrm{N}=137)(\%)\end{array}$ & $\begin{array}{l}\text { Nong bóng } \\
(\mathrm{N}=49)(\%)\end{array}$ & $\begin{array}{c}\text { Đăt giá đõ } \\
(\mathrm{N}=88)(\%)\end{array}$ & Giá trị p \\
\hline Tắc mạch & $1(0,73)$ & $0(0,0)$ & $1(1,1)$ & $0,54^{\mathrm{a}}$ \\
\hline Thúng ĐM can thiệp & $0(0,0)$ & $0(0,0)$ & $0(0,0)$ & $>0,99^{a}$ \\
\hline Tu máu đường vào & $1(0,73)$ & $1(2,04)$ & $0(0,0)$ & $>0,99^{a}$ \\
\hline Chảy máu đường vào & $0(0,0)$ & $0(0,0)$ & $0(0,0)$ & $>0,99^{a}$ \\
\hline Giả phinh đướng vào & $0(0,0)$ & $0(0,0)$ & $0(0,0)$ & - \\
\hline Suy thận cấp & $1(0,73)$ & $1(2,04)$ & $0(0,0)$ & $>0,99^{a}$ \\
\hline Cắt cụt chi & $2(1,5)$ & $0(0,0)$ & $2(2,3)$ & $0,54^{\mathrm{a}}$ \\
\hline NMCT & $1(0,73)$ & $0(0,0)$ & $1(1,1)$ & $>0,99^{a}$ \\
\hline Tứ vong & $0(0,0)$ & $0(0,0)$ & $0(0,0)$ & - \\
\hline Tống & $6(4,4 \%)$ & $2(4,1 \%)$ & $4(4,5 \%)$ & $>0,99^{a}$ \\
\hline
\end{tabular}

\section{Kết quá can thiệp}

\begin{tabular}{|c|c|c|c|c|}
\hline & $\begin{array}{c}\text { Tống } \\
(\mathrm{N}=137)(\%)\end{array}$ & $\begin{array}{l}\text { Nong bóng } \\
(N=49)(\%)\end{array}$ & $\begin{array}{c}\text { Đăt giá đõ } \\
(\mathbf{N}=88)(\%)\end{array}$ & Giá trị p \\
\hline ánh giá kết quả & & & & $0,67^{\mathrm{a}}$ \\
\hline $\begin{array}{c}\text { Thănh công } \\
\text { Thất bai }\end{array}$ & $\frac{132(96,4)}{5(3,6)}$ & $\frac{47(95,9)}{2(4,1)}$ & $\frac{85(96,6)}{3(3,4)}$ & \\
\hline
\end{tabular}

\section{Kết quả ngắn hạn:}

\section{Bảng 8: Tỷ lệ thành công, thât bại về lâm sàng.}

\begin{tabular}{|c|c|c|c|c|}
\hline & $\begin{array}{c}\text { Tống } \\
(\mathbf{N}=\mathbf{1 3 7})(\mathbf{\%})\end{array}$ & $\begin{array}{c}\text { Nong bóng } \\
(\mathbf{N = 4 7 ) ( \% )}\end{array}$ & $\begin{array}{c}\text { Đăt giá đỡ } \\
(\mathbf{N}=\mathbf{9 0})(\mathbf{\%})\end{array}$ & Giá trị p \\
\hline Đánh giá kết quả & & & & $>0,99^{\mathrm{a}}$ \\
\hline Thành công & $129(94,2)$ & $44(93,6)$ & $85(94,4)$ & \\
\hline Thất bại & $8(5,8)$ & $3(6,4)$ & $5(5,6)$ & \\
\hline
\end{tabular}

\section{BÀN LUẬN}

Tuổi trung bình của mẫu nghiên cứu là 70,4 \pm 10,9 tuổi (nhỏ nhất: 47 tuổi; lớn nhất: 97 tuổi). Nhóm đặt giá đõ có tuổi trung bình thấp hơn nhóm nong bóng đơn thuần $(68,5 \pm 10,4$ so với $73,8 \pm 10,9)$, khác biệt có ý nghĩa thống kê $(p=0,007)$ trong nghiên cứu của chúng tôi. Tuy nhiên, một số nghiên cứu của tác giả Kudo, Goode khi so sách tuổi trung bình hai nhóm đặt giá đỡ và nong bóng đơn thuần thì không có sự̛̣ khác biệt, Nam giới chiếm đa số trong mấu nghiên cứu (116 trường hợp, 84,7\%) cũng phù hợp với các tác giả khác. Nghiên cứu chúng tôi có tỷ lệ hút thuốc lá ở nhóm đặt giá đõ cao hơn nhóm nong bóng đơn thuần, khác biệt có ý nghĩa thống kê $(73,9 \%$ so với $55,1 \%, p=0,040)$. Khi so sánh với tác giả khác, ghi nhận cũng có tỷ lệ hút thuốc lá ở nhóm đặt giá đõ cũng cao hơn nhóm nong bóng đơn thuần, tuy nhiên khác biệt không có ý nghĩa thông kê, Kudo và cộng sự (76\% so với $56 \%, p=0,079$ ).

Nhóm nong bóng có tỷ lệ triệu chứng đau khi nghỉ cao hơn nhóm đặt giá đớ $(65,3 \%$ so với $48,9 \%, p=0,094)$, điều này khác biệt có ý nghĩa thống kê. Kết quả của chúng tồi cũng tương tự như nghiên cứu của Van và cộng sự. Nhìn chung 2 nhóm nong bóng và đặt giá đỡ có tỷ lệ phân độ Rutherford khác biệt không có ý nghĩa thống kê trong nghiên cứu chúng tôi, điều này cũng phù hợp với các nghiên cứu của tác giả khác. Nghiên cứu chúng tôi ghi nhận chỉ số ABI trung bình của chi trước can thiệp là $0,3 \pm 0,2$, thấp nhất là 0 , cao nhất là 0,9 . Đa số được phân loại nặng theo $A B I(<0,40)$ (96 trường hợp, 70,1\%).

Có 67 bệnh nhân $(48,9 \%)$ được phân độ $A$ theo TASC II và 70 bệnh nhân $(51,1 \%)$ được 
phân đô B theo TASC II (Bảng 7). Tỷ lệ phân độ tổn thương khác biệt có ý nghĩa thống kê ở 2 nhóm: nhóm nong bóng đơn thuần có tỷ lệ phân độ $B$ thấp hơn nhóm đặt giá đõ $(28,6 \%$ so với $63,6 \%, p<0,001)$.

Phương pháp vô cảm: Mẫu nghiên cứu có 123 bệnh nhân $(89.8 \%)$ được vô cảm bằng phương pháp tê tại chỗ khi can thiệp, số còn lại được gây mê nội khí quản. Kết quả này cũng phù hợp với các tác giả khác như Timaran và cộng sự, có tỷ lệ vô cảm bằng phương pháp tê tại chổ lần lượt là $79 \%, 100 \%$.

Phương pháp can thiệp: Trong nghiên cứu chúng tôi ghi nhận thời gian can thiệp trung bình là $150 \pm 51,3$ phút. Vị trí đường vào can thiệp phổ biến nhất trong nghiên cứu chúng tôi là ĐM đối bên (64 trường hợp, 46,7\%), tiếp theo là ĐM cùng bên (57 trường hợp, 41,6\%). Ngoài ra có 13 trường hợp được tiếp cận từ tay xuống $(9,5 \%)$ và 3 trường hợp tiếp cận từ khoeo lên $(2,2 \%)$. Tỷ lệ vị trí đường vào khác biệt có ý nghĩa thống kê ở 2 nhóm: nhóm nong bóng đơn thuần có tỷ lệ tiếp cận từ $Đ M$ đối bên cao $(65,3 \%)$, trong khi nhóm đặt giá đõ có tỷ lệ tiếp cận từ ĐM cùng bên cao (48,9\%). Điêu này có sự khác biệt khi so sánh với tác giả Pulli và cộng sự trong phân nhóm TASC II $A$ và $B$ của nghiên cứu, vị trí đường vào can thiêp hầu hết là ĐM cùng bên (80 trường hợp, $70 \%)$, ĐM đối bên chỉ có 17 trường hợp (15\%), 5 trường hợp được tiếp cận từ tay xuống $(4,5 \%)$ và 12 trường hợp mở ĐM đùi vùng bẹn cùng bên $(10,5 \%)$. Can thiệp tầng dưới chậu kèm theo ở hâu hết mẫu nghiên cứu chúng tôi, có 88 trường hợp $(64,2 \%)$ được can thiệp dưới ĐM chậu kèm theo: 78 trường hợp $(56,9 \%)$ được can thiệp ở tầng đùi-khoeo, 2 trường hợp can thiệp ở tầng dưới gối $(1,5 \%)$, và 8 trường hợp được can thiệp ở cả tầng đùikhoeo và dưới gối $(5,8 \%)$. Tỷ lệ này khác biệt có ý nghĩa thống kê ở 2 nhóm: nhóm nong bóng đơn thuân có tỷ lệ được can thiệp kèm theo cả tâng đùi-khoeo và dưới gối cao hơn nhóm đặt giá đõ $(16,3 \%$ so với $0 \%)$.

Nghiên cứu ghi nhân kích thước bóng trung bình của nhóm nong bóng là $6,5 \pm 0,7 \mathrm{~mm}$. Trong đó, tất cả chúng tôi dùng loại bóng không áp lực. Kích thước giá đõ̃ trung bình của nhóm đặt giá đõ là 7,3 $\pm 0,6 \mathrm{~mm}$. Chúng tôi ghi nhận đa số sử dụng giá đõ tự bung, chiếm 93,2\% (82 trường hợp). Giá đõ̃ nội mạch tự bung có độ linh hoạt cao, dễ dàng thích ứng với sự thay đổi thành mạch và phù hợp trong những trường hợp cấu trúc mạch máu uốn lượn như động mạch chậu ngoài. Ngược lại, giá đõ nội mạch bung bằng bóng có lực đồng tâm cao, chính xác vị trí hạ đặt và thường đặt giá đõ đối nhau trong tổn thương hai chậu chung. Động mạch chậu chung có kích thước lớn, thẳng, và thường vôi hóa, dể tái hẹp và bóc tách sau can thiệp còn động mạch chậu ngoài có kích thước nhỏ hơn, xoắn vặn trong tiểu khung. Do đó, giá đõ bung bằng bóng phù hợp cho chậu chung hơn chậu ngoài

Biển chứng can thiệp: Nhóm nong bóng đơn thuần có 2 trường hợp (4,1\%), nhóm đặt giá đõ có 4 trường hợp (4,5\%). Sự khác biệt 2 nhóm không có ý nghĩa thống kê.

Các biến chứng của nhóm nong bóng gồm thủng mạch máu và tụ máu, biến chứng này cùng xảy ra trên bệnh nhân được can thiệp cả tầng chậu, đùi khoeo. Đường vào cùng bên can thiệp, sau khi nong bóng tầng chậu kết thúc phẩu thuật viên rút sheath và chọc xuôi dòng để đặt lại sheath, tiếp tục can thiệp đùi khoeo. Chụp kiểm tra khi kết thúc can thiệp ghi nhận có thoát mạch, sưng nề xung quanh vị trí chọc kim ở bẹn. Tiển hành băng ép có trọng điểm và theo dõi sát. Khối máu tụ không tiến triển thêm những ngày sau đó, tình trạng chân được cải thiện sau can thiêp.

Các biến chứng của nhóm đặt giá đỡ gồm tắc mạch, thủng mạch máu gây tụ máu, suy thận cấp, nhồi máu cơ tim. Trường hợp thứ 1 xảy ra trên bệnh nhân tắc động mạch chậu chung phải, đường vào cùng bên tổn thương. Sau can thiệp khoảng 3 tiếng, ghi nhận tình trạng chân tím, lạnh và giảm vận động cảm giác, mạch khoeo, mu chày phải không bắt được và siêu âm ghi nhận huyết khối đùi khoeo phải. Tiến hành mở động mạch đùi phải, dùng forgarty lấy huyết khối đùi chung, nông và sâu phải. Sau đó tình trạng chân bệnh nhân có cải thiện rõ. Trường hợp thứ 2 xảy ra sau can thiệp chân phải cải thiện tốt hơn các triệu chứng so với trước mổ. Nhưng theo dõi sau 03 ngày, chân can thiệp đột ngột tím, lạnh và mất vận động, cảm giác. Siêu âm ghi nhận tắc không hoàn toàn ĐM đùi khoeo và dưới gối do huyết khối. Tiến hành thám sát không giữ được chân, cắt cụt $1 / 3$ giữa đùi phải. Qua 2 trường hợp trên, chúng tôi cần rút kinh nghiệm trong các kỹ thuật chọc kim, đặt dụng cụ và các thao tác thật nhẹ nhàng, tránh làm thổ bạo có thể dẫn đến bong tróc mảng xơ vữa gây tắc đầu xa. Bên cạnh đó, liều dùng heparin cũng cần tính toán sao cho phù hợp để tránh huyết khối ngay vị trí đặt dụng cụ đường vào. Trường hợp thứ 3 xảy ra trên bệnh nhân loét, hoại tử bàn ngón I chân trái, có hẹ động mạch chậu chung trái với phân độ TASC II A kèm hẹp động 
mạch đùi nông trái. Tiền sử bệnh có tăng huyết áp, đái tháo đường và suy thận mạn giai đoạn cuối. Bệnh nhân được đặt giá đõ nội mạch động mạch chậu chung trái, đùi nông trái kèm tháo bàn ngón I. Hậu phấu bệnh nhân được chẩn đoán NMCT thành trước killip II, được điều trị nội khoa kèm cẳng bàn chân tím, lạnh được cắt cụt $1 / 3$ giữa đùi trái. Bệnh xuất viện sau gần 30 ngày điều trị. Trường hợp thứ 4 xảy ra trên bệnh nhân có đau khi nghỉ chân phải, mạch đùi, khoeo và chày trước, sau chân phải khổng bắt được. CTA ghi nhận tắc động mạch chậu ngoài phải kèm tắc động mạch đùi nồng phải đoạn giữa. Bệnh nhân được can thiệp đặt giá đõ động mạch chậu phải, đùi nông phải. Chụp kiểm tra sau can thiệp, ghi nhận huyết khối gây tắc cấp động mạch đùi chung, sâu chân phải. Bệnh nhân được tiển hành mở động mạch đùi lẩy huyết khối. Chụp kiểm tra thổng tốt hệ mạch máu chân phải sau lấy, hậu phẫu chân phải hết đau nhức. Bệnh nhân xuất viện sau 12 ngày điều trị. Qua đây chúng tôi nhận thấy vấn đề theo dõi hậu phẫu các biến chứng can thiệp đóng vai trò quan trọng. Việc đánh giá tình trạng tưới máu chân sau can thiệp bằng thăm khám lâm sàng, đo $\mathrm{Sp02}$ và siêu âm nhằm phát hiện và xử trí kịp thời các biến chứng của can thiệp nội mạch. Bênh cạnh đó, điều trị ổn định các bệnh phối hợp giúp cho bệnh nhân có kết quả điểu trị tốt đẹp hơn sau can thiệp.

Đánh giá kêt quả: Nghiên cứu chúng tôi ghi nhận tỷ lệ thành công về kỹ thuật của nhóm nong bóng và đặt giá đỡ lân lượt chiếm $95,9 \%$ và $96,6 \%, P=0,67$. Tỷ lệ thất bại của nhóm nong bóng và đặt giá đỡ lần lượt chiếm 4,1\% (2 trường hợp) và $3,4 \%$ (3 trường hợp). Thất bại nhóm nong bóng xảy ra trong quá trình can thiệp, 01 trường hợp nong bằng bóng $6 \times 60 \mathrm{~mm}$ vào tổn thương tắc ĐM chậu chung, chụp kiểm tra có bóc tách quyết định đặt giá đố 7x100 mm. Và 01 trường hợp khác cũng xảy ra bóc tách khi nong bằng bóng $7 \times 80 \mathrm{~mm}$ vào tổn thương hẹp ĐM chậu chung, sau đó tiến hành đặt giá đỡ 7x100 mm. Qua 2 trường hợp này, chúng tôi nhận thấy mặc dù đường kính ĐM chậu chung trung bình người việt nam là $7,7 \mathrm{~mm}$. Tuy nhiên, không phải ngay từ đầu chúng ta tiến hành nong ngay bóng có kích thước $6,7 \mathrm{~mm}$ mà tùy theo kích thước thực tế trên bệnh nhân, mức độ vôi hóa của $Đ M$, hình dạng và cấu trúc uốn lượn trong khung chậu... Theo kinh nghiệm chúng tồi, thường khởi đâu bằng bóng có đường kính $3-4$ $\mathrm{mm}$, sau đó nong dần lên những bóng có kích thước lớn hơn để trách bóc tách, vỡ mạch và tụ máu, hoặc gây huyết khối đầu xa. Thất bại nhóm đặt giá đỡ xảy ra trên 03 trường hợp gồm 02 trường hợp cắt cụt và 01 trường hợp tắc ĐM cấp do huyết khối.

Tỷ lệ thành công ngắn hạn của nhóm nong bóng và đặt giá đỡ là $93,6 \%$ và $94,4 \%, P>0,99$. Trong quá trình can thiệp, chúng tôi nhận thấy có những yếu tố giúp can thiệp nội mạch đạt kết quả tốt như nắm rõ cấu trúc giải phẫu, kích thước hình ảnh và góc chiếu phù hợp. Giải phẫu ĐM chậu nằm hoàn toàn trong khung chậu, phía sau phúc mạc và bị ảnh hưởng bởi khung chậu, ruột, các nhánh ĐM mạc treo tràng dưới, nhánh ĐM chậu trong, nhánh ĐM mũ chậu sâu, bàng quang và đôi khi là khớp gối nhân tạo. Do đó dể tạo hình ảnh giả các tổn thương tắc, hẹp ĐM chậu. Để tránh trường hợp này, bệnh nhẩn cần được chuẩn bị chu đáo từ nhịn ăn, uống trên 8 giờ trước can thiệp, vị trí bệnh nhân nằm trên bàn mổ phù hợp tránh trùng lấp các dị vật như miếng dán điện cực máy đốt, thanh kim loại cản từ. Kích thước hình ảnh và góc chiếu cần chỉnh sao cho vừa thấy rõ toàn bộ cấu trúc ĐM chậu, tránh quá nhỏ hoặc quá lớn dẫn đến xác định không chích xác vùng hạ đặt giá đõ hoặc nong bóng quá chiều dài tổn thương gây bóc tách, sang chấn vùng ĐM chậu bình thường. Theo tác giả Keisuke, ghi nhận giữa kích thước khung ảnh $30 \mathrm{~cm}$ và $20 \mathrm{~cm}$ khi soi chiếu khung chậu trong quá trình can thiệp ĐM chậu thì kích thước khung ảnh $20 \mathrm{~cm}$ cho thấy cấu trúc ĐM chậu rõ hơn, xác định ranh giới tổn thương và không tổn thương phù hợp hơn. Ngoài ra, góp phần đạt kết quả ngắn hạn tránh các biến chứng, tái hẹp còn phải kể đên việc chọn lựa các loại bóng, giá đõ cho phù hợp cả về đường kính và chiều dài. Đây cũng là những khó khăn mà chúng tôi găp phải trong nghiên cứu này. Do đó, cần dự trù các phương án có thể xảy ra và chuẩn bị dụng cụ đây đủ sẽ giúp đạt được kết quả can thiệp ngắn hạn tốt hơn.

\section{KẾT LUÂNN}

Nong bóng và đặt giá đõ trong điều trị tắc động mạch chậu tổn thương TASC II $A, B$ là ít xẩm lấn, an toàn, hiệu quả, thời gian nằm viện ngắn, hồi phục nhanh. Cả hai phương pháp đều cải thiện các triệu chứng lâm sàng và cận lâm sàng sau can thiệp, ít biến chứng. Tỷ lệ thành công về lâm sàng ở giai đoạn ngắn hạn của phương pháp nong bóng và đặt giá đỡ tương đương nhau.

\section{TÀI LIỆU THAM KHẢO \\ 1. Nguyễn Lân Việt, Phạm Việt Tuân, Phạm}


Mạnh Hùng (2010), "Nghiên cứu mô hình bệnh tât ở bệnh nhân điêuu trị nôi trú tai Viên Tim mạch Việt nam trong thời gian 2003-2007". Tạp chí Tim mạch học Việt Nam, số 52, tr. 11-17.

2. Goode SD, Cleveland TJ, Gaines (2013). "Randomized clinical trial of stents versus angioplasty for the treatment of iliac artery occlusions (STAG trial)". British Journal of Surgery; 100(9): pp.1148-53.

3. Kudo T, Chandra FA, Ahn SS (2005) "Long-term outcomes and predictors of iliac angioplasty with selective stenting", J Vasc Surg, 42(3): pp.466-75.

4. Taylor M Spence, John W. York (2010), "Lower Extremity Arterial Disease: Decision Making and Medical Treatment", Rutherford's Vascular Surgery, 7 ed., 2, Chap 104, pp.1593 - 1612.

5. Timaran, et al (2001), "External iliac and common iliac artery angioplasty and stenting in men and women", J Vasc Surg; Vol 34(3), pp.440-446.

6. Van Haren R.M., et al (2017), "Endovascular treatment of TransAtlantic Inter- Society Consensus $D$ aortoiliac occlusive disease using unibody bifur- cated endografts", ] Vasc Surg, 65(2): p. 398-405.

7. Rutherford RB, Baker JD, Ernst C, Johnston KW, Porter JM, Ahn S, Jones DN (1997) "Recommended standards for reports dealing with lower extremity ischemia: revised version". J Vasc Surg, 26, pp.517-538.

8. Pulli $R$, Dorigo $W$, Fargion $A$, Innocenti AA, Pratesi G, Marek J, Pratesi C (2011), "Early and long-term comparison of endovascular treatment of iliac artery occlusions and stenosis". J Vasc Surg, 53(1), pp.92-98.

\section{MộT SỐ YẾU TỐ LIÊN QUAN ĐẾN MÂT Độ XƯƠ'NG Ở NGƯỜI BỆNH CAO TUỔI TẠI BỆNH VIÊ̂N LÃO KHOA TRUNG ƯƠNG}

\section{TÓM TẮT}

Nghiên cứu cắt ngang mục tiêu phân tích một số yếu tố liên quan đến mật độ xương ở người cao tuổi điều trị tại bệnh viện Lão Khoa Trung Ương. 300 người bệnh đến khám tại khoa khám bệnh, khoa khám bệnh theo yêu cầu và điều trị nôi trú tại khoa nội tiết và cơ xương khớp Bệnh viện Lã̃o Khoa Trung Ương thỏa mãn các điều kiên (i) Tuổi $\geq 60$, (ii) Đồng ý tham gia nghiên cứu. Loại ra khỏi nghiên cứu các đối tượng (i) Đái tháo đường, (ii) Loãng xương thứ phát, (iii) Đã điều trị loãng xương. Kết quả cho thấy Phần lớn loãng xương găp ở nhóm tuổi $\geq 80$. Tuổi trung bình của nhóm loã̉ng xương là $73,3 \pm 7,6$. Chủ yếu găp ở nư giới (93,6\%). Mật độ xương giảm dân theo tuổi ở cả 2 vị trí $C S T L$ và $C X \bigoplus(p<0,05)$. Khả năng người bệnh tập thể dục không có loãng xương cao gấp 1,8 lần người không tập thể dục $(95 \% \mathrm{CI}: 1,3-2,4)$. Nguy cơ người có bệnh lý nền xuất hiện tình trạng loãng xương cao gấp 2,37 lần những người không có bệnh lý nền (95\%CI: 1,8 - 3,1). Mật độ xương ở cột sống thắt lưng và mât đô xương ở cổ xương đùi có mối tương quan nghịch với Cholesterol TP, Triglycerid và $\mathrm{HDL}-\mathrm{C}$ $(p<0,01)$. Ngược lai, mật độ xương ở côt sống thắt lưng và mật độ xương ở cổ xương đùi có mối tương quan thuân với $L D L-C$.

Tư khoá: mật độ xương; người già;

\section{SUMMARY}

*Bênh viện Lão Khoa Trung Uơng

**Bênh viện Bach Mai

***Đai hoc Y Hà Nôi

Chịu trách nhiệm chính: Hoàng Thị Bích

Email: mimosahoangbich@gmail.com

Ngày nhận bài: 12.7.2021

Ngày phản biên khoa hoc: 8.9.2021

Ngày duyệt bài: 14.9.2021

\section{SOME FACTORS RELATED TO BONE DENSITY IN GERIATRIC PATIENTS AT THE NATIONAL GERIATRIC HOSPITAL}

A cross-sectional study aimed at analyzing some factors related to bone density in elderly people treated at the National Geriatric Hospital. 300 patients visited the medical examination department, ondemand examination department and inpatient treatment at the Department of Endocrinology and Musculoskeletal system at the National Geriatric Hospital satisfying the following conditions (i) Age $\geq$ 60, (ii) Agree to participate in the study. Excluded from the study subjects (i) Diabetes, (ii) Secondary osteoporosis, (iii) Treated osteoporosis. The results show that the majority of osteoporosis occurs in the age group $\geq 80$. The mean age of the osteoporosis group is $73.3 \pm 7.6$. Mainly seen in women (93.6\%). Bone density decreased with age in both lumbar spine and vertebral column $(p<0.05)$. Patients who exercise without osteoporosis are 1.8 times more likely than those who do not exercise (95\% CI: $1.3-2.4$ ). The risk of people with underlying medical conditions developing osteoporosis is 2.37 times higher than those without underlying disease (95\% CI: $1.8-3.1$ ). Bone density in lumbar spine and bone density in femoral neck were negatively correlated with cholesterol TP, Triglyceride and HDL - C $(p<0.01)$. In contrast, bone density in the lumbar spine and bone density in the femoral neck were positively correlated with LDL-C.

Keywords; osteoporosis density; old person;

\section{I. ĐĂT VẤN ĐỀ}

Loãng xương là bệnh lý ảnh hưởng đến toàn bộ hệ thống xương, giảm sức mạnh của xương, gia tăng nguy cơ gãy xương ảnh hưởng lớn tới chất lượng cuộc sống có thể gây tử vong ở người 